\title{
ANÁLISE DA PLANIFICAÇÃO DA POLÍTICA NACIONAL DE SANEAMENTO BÁSICO NO MUNICÍPIO DE PELOTAS - RS
}

\section{ANALYSIS OF THE PLANNING OF THE NATIONAL BASIC SANITATION POLICY IN THE MUNICIPALITY OF PELOTAS - RS}

\section{Cristine Jaques Ribeiro ${ }^{1}$ \\ Caroline Kruger Guimarães ${ }^{2}$ \\ Nino Rafael Medeiros Kruger ${ }^{3}$}

\section{Resumo}

O artigo objetiva analisar a planificação da Política Nacional de Saneamento Básico (PNSB) no município de Pelotas-RS, problematizando uma possível mudança de paradigma político desenvolvido através de novas retóricas que camuflaram a perpetuação do desenvolvimento de velhas políticas no Brasil. Para tanto, se busca compreender o modelo de Estado de Bem-Estar Social que se desenvolveu no país e a racionalidade oculta nas políticas públicas brasileiras, embasando uma apreciação relacional do Plano Municipal de Saneamento Básico (PMSB) na cidade em estudo. O desenvolvimento de tais análises visa compreender não somente de que forma o PMSB normatiza a execução da política nacional, mas ainda, quais seriam os objetivos, valores e discursos que se colocam em disputa, nas transformações em curso, e para qual horizonte aponta a reorganização estrutural das políticas sociais brasileiras.

Palavras-chave: Política Nacional de Saneamento; Plano Municipal de Saneamento; Estado; Políticas Públicas; Planificação.

\footnotetext{
${ }^{1}$ Doutorado em Serviço Social. Docente do Curso de Serviço Social/UCPEL. Docente do Curso de Pósgraduação em Politica Social e Direitos Humanos. Pesquisadora na area dos Movimentos Sociais. Coordena o Grupo de estudos e pesquisa CNPQ em Questão Agrária, Urbana e Ambiental - Observatório dos Conflitos da Cidade. E-mail: cristinejrib@gmail.com

${ }^{2}$ Doutoranda em Administração de Organizações pela Universidade de São Paulo (USP-RP). Pesquisadora do Centro de Estudos em Gestão e Políticas Públicas Contemporâneas (Gpublic), e do Golden for Sustentability Brazil. E-mail: nino.kruger@sou.ucpel.edu.br

${ }^{3}$ Mestrando em Política Social pela Universidade Católica de Pelotas (UCPEL). Membro do Grupo de Pesquisa CNPQ em Questão Agrária, Urbana e Ambiental - Observatório de Conflitos da Cidade. E-mail: contatorafaelkruger@hotmail.com
} 


\section{Abstract}

The article aims to analyze the planning of the National Policy of Basic Sanitation (NPBS) in the city of Pelotas- RS, problematizing a possible change of political paradigm developed through new rhetoric that camouflaged the perpetuation of the development of old policies in Brazil. In order to do so, the aim is to understand the State of Social Welfare model that has developed in the country and the hidden rationality in Brazilian public policies, supporting a relational appreciation of the Municipal Basic Sanitation Plan (MBSP) in the city under study. The development of such analyzes aims not only to understand how the MBSP regulates the execution of the national policy, but also, what are the objectives, values and discourses that are in dispute, in the ongoing transformations, and for what horizon does the reorganization structure of Brazilian social policies

Keywords: National Sanitation Policy; Municipal Sanitation Plan; State; Public Policy; Planning.

\section{INTRODUÇÃO}

A Política Nacional de Saneamento Básico (PNSB) busca a integração complexa de políticas de relevante interesse social, a participação democrática do Estado e da sociedade civil para sua planificação, exigindo assim, o envolvimento de inúmeros profissionais das mais variadas áreas do conhecimento, bem como representantes da sociedade civil. Desta forma, aponta para uma reorganização na estrutura de seu modelo de execução, pautado pela democracia participativa.

Neste ínterim, entende-se enquanto necessário, que aja rigor teórico-metodológico na construção dos documentos que intentam sua realização, para que os agentes envolvidos possam reconhecer-se mutuamente na execução dos processos, ainda, para que este se dê a contento do especificado na norma. A não ser que a mesma se desenvolva apenas de forma retórica, sem a rela intenção de possibilitar o agenciamento de vetores de transformação que possibilitem mudanças cognitivas e paradigmáticas em seu desenvolvimento.

Pois, uma primeira aproximação ao desenvolvimento histórico das políticas de saneamento básico brasileiras aponta para o fato de que estas transcorreram por imposição política e econômica, frequentemente de forma externa, sendo motivadas por transformações do cenário econômico internacional, porém, apresentando um discurso relativamente próximo. Assim, neste estudo, reconstruir-se-ão tais processo relacionando-os com o desenvolvimento 
do Estado de Bem-Estar Social Brasileiro (EBESB), visitando o desenvolvimento das políticas habitacionais para a nação, para assim ancorar as discussões sobre a legislação atual para o saneamento básico e o documento que visa sua planificação no município de Pelotas/RS.

Tendo em vista que as recentes alterações nas legislações específicas, desenvolvidas para o acesso a recursos públicos federais através de programas criados a partir do ano de 2007, são apontados enquanto direcionados a incentivar o crescimento econômico através de tais investimentos para o aumento da produtividade, diminuição das desigualdades regionais e desenvolvimento social (BRASIL, 2007), este estudo busca desenvolver análises intentando compreender os objetivos das alterações nas legislações e expansão das políticas públicas, que apontavam para uma maior participação social através das ferramentas e instrumentos desenvolvidos por estas.

Tal problematização, posteriormente aprofundada, tem enquanto marco a crise internacional que teve seu auge no ano de 2008 - onde o cenário internacional apontava para uma grande recessão (GIMENO, 2017, p. 38), e que serviu substancialmente para alterar os rumos de desenvolvimento e execução das políticas públicas no Brasil. Esta reflexão ainda deve ser somada a criação dos Planos Municipais de Saneamento Básico (PMSB), que no município observado, deu-se por imposição para o acesso de recursos que visavam o desenvolvimento de obras através do financiamento do Programa de Aceleração do Crescimento (PAC) (BRASIL, 2007).

Importante esclarecer, que o PAC se fundamenta em três eixos de atuação para o desenvolvimento de projetos de infraestrutura urbana: Saneamento Básico, Mobilidade Urbana e Habitação, para os quais a Prefeitura Municipal de Pelotas juntamente com a autarquia responsável pelos serviços de saneamento - Serviço Autônomo de Saneamento de Pelotas (SANEP) - constituíram uma série de projetos para o acesso a recursos a partir do ano de 2009.

Através de estudos relacionais das políticas irá desenvolver-se este estudo, questionando as raízes e orientação do EBESB, das políticas para habitação, bem como as alterações na legislação Federal para o saneamento e sua planificação através da reflexão sobre o plano local de saneamento básico do município de Pelotas-RS. Refletindo sobre a possibilidade de uma mudança de paradigma político, e uma plausível reorientação nas políticas sociais em curso no Brasil que possa ser observada nesta relação. Assim, questiona-se: tais mudanças representam algo novo, e podem ser encaradas enquanto uma transformação? As alterações atuais na legislação podem vir a causar uma mudança cognitiva no que tange a orientação da política? O próximo tópico buscará refletir sobre estes questionamentos. 


\section{DESENVOLVIMENTO DA POLÍTICA DE SANEAMENTO BÁSICO E DO ESTADO DE BEM-ESTAR SOCIAL BRASILEIRO: EXISTE UMA MUDANÇA DE PARADIGMA NO ATUAL CONTEXTO?}

Em trabalho recente, que busca a compreensão da reestruturação dos Estados de BemEstar, bem como da mudança de paradigma para as políticas sociais Europeias, José Adelantado Gimeno (2017) lança reflexão sobre a transformação nos modelos de Estados de Bem-Estar Protetores para Inversores, destacando a existência de diferentes perspectivas e nomenclaturas que são utilizadas na literatura especializada para abordar tal temática. Estando todas estas voltadas para compreensão das transformações ocorridas na Europa.

Refletindo sobre uma possível reorientação estrutural das políticas sociais brasileiras, primeiramente faz-se necessário situar o Brasil e o modelo de proteção social desenvolvido no país ao longo das últimas décadas, para que se possa visualizar sua orientação original e posteriormente refletir sobre uma possível transformação.

Assim, destaca-se que em países em desenvolvimento ou subdesenvolvidos o surgimento dos Estados de Bem-Estar se deu mais como uma decisão política do próprio Estado, diferentemente de como se desenvolveu na Europa, que foi resultante de conflitos sociais (DRAIBE, 1989; BARCELLOS, 1983). No Brasil mais especificamente, o surgimento se dá a partir de decisões estatais de caráter político, com vistas à regulamentação da organização laboral dos trabalhadores e centralização das ações estatais, que buscavam integrar a economia e regulamentar os fatores de produção entre os anos de 1930 e 1964 (BARCELLOS, 1983).

Este modelo profundamente conservador utilizava-se do autoritarismo, que Barcellos (1983) aponta enquanto evidente na repressão aos movimentos de trabalhadores e ações de cunho paternalista. Para Sônia Draibe (1989), a formação do EBESB corresponde a um movimento de criação da base institucional-legal para as políticas sociais através do qual desenvolveram-se a produção legislativa trabalhista, a criação dos institutos de aposentadoria e pensões, destacando que:

o período é também fértil em alterações nas áreas de política de saúde e de educação, onde se manifestam elevados graus de 'nacionalização' das políticas sob a forma de centralização no Executivo Federal, de recursos e de instrumentos institucionais e administrativos e resguardos de algumas competências típicas da organização federativa do país (DRAIBE, 1989, p. 08). 
No que diz respeito a este desenvolvimento e sua associação às políticas de saneamento, Cynamon (1986) traz importantes apontamentos que auxiliam na compreensão destes processos e que serão fundamentalmente importantes para as reflexões posteriores. Entre eles, o início do desenvolvimento do sistema de saneamento no Brasil, e a exploração dos mesmos, que tem como marco o ano de 1857, onde na cidade do Rio de Janeiro começam a ser desenvolvidos estes trabalhos por companhias privadas internacionais, sendo executado por mais de cinquenta anos por estas empresas, que por não oferecerem um serviço considerado de qualidade, acabaram por perder os direitos de prestação de serviços para o Estado no início do século XX (CYNAMON, 1986).

Já na década de 1940, pelos mesmos motivos - a falta de qualidade nos serviços impulsionado pelo movimento anterior descrito por Draibe (1989), ocorre o surgimento da Engenharia Sanitária Brasileira, através da qual se dá início ao surgimento das primeiras autarquias e mecanismos de financiamento para o abastecimento de água (CYNAMON, 1986). Deve-se destacar, contudo, que neste período as políticas de saneamento ainda não se vinculavam às políticas de saúde, estando centralizada no Ministério dos Negócios da Educação e Saúde Pública, sob a Lei 19.402/1930 (BRASIL, 1930).

Neste período ocorre também a estatização da Previdência Social, anteriormente organizada pelos empregadores, passando a União a contribuir com a mesma, no intuito de desonerar o empresariado em parte de seus custos (MEDEIROS, 2001). Vislumbra-se assim, em tais estratégias a centralização administrativa das políticas por parte do Estado, o que Barcellos (1983) destaca enquanto uma manobra de acirramento do populismo estatal, através do qual criam-se os marcos legais para a o funcionamento do Estado Democrático.

Borja (2014), resgatando as origens da política de saneamento básico brasileira, sobretudo neste período, afirma que a mesma não reconhecia o protagonismo da gestão democrática, desenvolvendo-se de forma voltada ao alinhamento estatal e ao ideário de organizações internacionais, demonstrando um engajamento por parte das elites nacionais para a subordinação econômica as diretrizes do capital internacional, consequentemente estimulando a fragilização da soberania nacional.

Já no ano de 1951, se desenvolveram as medidas de centralização das ações estatais (BARCELLOS, 1983), e foi aceito pelo Congresso Nacional o primeiro projeto para criação de um fundo voltado a resolver os problemas de abastecimento de água e esgotos, que ganhavam destaque diante do crescimento das cidades, impulsionado pelo processo de industrialização e 
urbanização nacional, ficando a cargo do Ministério de Viação e Obras a administração deste fundo (CYNAMOM, 1986).

Desenvolve-se assim, um plano de investimentos através da cobrança de taxas de prestação de serviços, da disponibilização de recursos aos municípios pelo Governo Federal e ainda, da concessão de parte dos recursos arrecadados com o Imposto de Renda para garantia das demandas inerentes ao desenvolvimento das obras. Este movimento, impulsionou o início do desenvolvimento da política de saneamento no país, que como já apontado, fomentou o surgimento do Estados de Bem-Estar em países em desenvolvimento ou subdesenvolvimento, agregado a decisão política de cada Estado.

Estas estruturas que se desenvolveram até o ano de 1964 em um processo continuado por mais de três décadas, acabaram por ser completamente desreguladas, diante do golpe militar. A partir de então, segundo Draibe (1989), desenvolvem-se políticas de massa, com cobertura relativamente ampla, organizadas através de sistemas públicos em duas linhas distintas: uma de caráter compensatório assistencialista, e outra, de caráter produtivista, voltada para a elaboração de políticas sociais que contribuíssem para o processo de crescimento econômico do país.

Nesse cenário, ocorreu a alteração na administração do fundo para água e esgoto, através do Decreto 200, de 25 de fevereiro de 1967 (BRASIL, 1967), que colocou a condução das políticas de saneamento no país a cargo do Ministério do Interior, impondo no Art. 10 a descentralização das atividades da administração Federal para a órbita privada, mediante contratos e concessões (GAMA, 2010), que posteriormente, acabou sendo transferido ao Banco Nacional de Habitação (BNH), criado em agosto de 1964 através da Lei 4.380, objetivou segundo a legislação instituinte resolver os problemas de saneamento e habitação no país (CYNAMON, 1986), ocultando desta forma sua essência, que voltava-se para o controle da classe trabalhadora (SILVA, 1989), através de políticas compensatórias ocasionadas pelo desenvolvimento do capitalismo (DRAIBE, 1989).

A Lei 5.318 promulgada em 26 de setembro de 1967, institui a criação do primeiro Conselho Nacional de Saneamento (CONSANE) (BRASIL, 1967b), que vincula a Política Nacional de Saneamento à Política Nacional de Saúde. Importante complementar, que não houve o desenvolvimento de instrumentos de aproximação ou democratização de gestão da política, que continuou a ser abordada de forma tecnicista, autoritária e verticalizada.

[...] sob o argumento do tecnicismo e da "cidadania responsável", de acordo com os quais a participação na gestão do saneamento (e das 
águas) estaria restrita àqueles que detêm os conhecimentos técnicos necessários ao debate (CAUBET, 2004, p. 147).

Assim, se desdobra o desenvolvimento da política de saneamento brasileira, que passou a ser trabalhada pela equipe técnica do BNH (CYNAMON, 1986). Deste modo, em 1969 através do decreto 949, o BNH que em 1967 fora passado do Ministério da Fazenda para o Ministério do Interior, é autorizado a administrar os recursos do saneamento, e aplicar em seu financiamento além de recursos próprios, recursos advindos do Fundo de Garantia por Tempo de Serviço (FGTS), criando a carteira de saneamento. Em 1971, mesmo ano de promulgação da Lei no 5.762 de 14 de dezembro, que transforma o BNH em empresa pública, de personalidade jurídica de direito privado com patrimônio próprio, institui-se o primeiro Plano Nacional de Saneamento, o PLANASA.

Cabe destacar, que segundo a legislação vigente coube a partir de então ao BNH a gestão do FGTS, operando por intermédio de bancos privados e/ou públicos, bem como de agentes promotores, tais como as companhias habitacionais e de água e esgoto, passando a desenvolver desta maneira, a transferência de recursos e fundos estatais para agentes privados.

Para Medeiros (2001), no período marcado pela criação da base institucional e legal do EBESB, o particularismo se expressou no corporativismo. Adquirindo posteriormente um caráter clientelista, manifesto em uma tendência a feudalizar territórios, colocando-os sob o domínio de grupos e personalidades. Sonia Draibe (1989) corrobora com este pensamento, apontando para ampliação de políticas assistencialistas e clientelistas, que afetaram o desenvolvimento das políticas públicas em sua qualidade.

Até as reformas ocorridas na década de 1980, o EBESB caracterizava-se pela centralização política e financeira em nível federal, fragmentação institucional, tecnocratismo, e uso clientelístico das políticas sociais (MEDEIROS, 2001), não funcionando como mecanismo redistributivo, direcionado à legitimação da ordem política.

Após um hiato democrático, possibilitado pela generalização das lutas sociais no país entre as décadas de 1970 e 1980, que resultou na promulgação da Constituição Federal em 1988 (CF), abriram-se caminhos para o direcionamento de substantivos avanços para a positivação de direitos sociais, possibilitados pela participação da sociedade civil no processo. Contudo, novamente se deram fragmentação, focalização e seletividade na execução das políticas públicas, ocultados em um discurso de desenvolvimento (MEDEIROS, 2001).

Uma década antes da extinção do BNH, ocorrida em 1986 pela incorporação deste à Caixa Econômica Federal, o PLANASA já não estava em funcionamento (GAMA, 2010), fato este 
que dissolveu no início da década de 1970 o debate acerca do saneamento básico, tornando o mesmo a emergir na década de 1990, diante de interferências internacionais, sobretudo do Banco Mundial, sob as deliberações do "Consenso de Washington", através do qual se passa a tencionar pelo avanço das políticas neoliberais no Brasil.

Neste movimento se dá a fundamentação da retórica para o retorno a lógica da privatização, contra a qual os movimentos sociais organizados haviam lutado nas décadas anteriores, o que pode ser observado no comprometimento firmado com o Fundo Monetário Internacional (FMI) em 1999, pelo Estado nacional, que se deu através de um governo de centro direita, que tencionou neste período pelo êxito das políticas neoliberais no país, através do qual se intentou tomar dos municípios a titularidade dos serviços de saneamento para transferência ao Governo Federal pelo PL 4.147/2001, em uma manobra apontada enquanto facilitadora para seu repasse à iniciativa privada (CYNAMON, 1986).

O projeto que acabou por ser negado em sua totalidade no Congresso Nacional diante do enfrentamento feito por parte de movimentos sociais, sobretudo pelo Movimento Municipalista Brasileiro (CYNAMON, 1986), acabou por voltar à pauta anos mais tarde, desta vez sob orientação de um governo até então de oposição.

Os desdobramentos de tal processo ratificam o fato de que o desenvolvimento de estratégias para concessões de serviços públicos a iniciativa privada, além de não ser um processo novo no país, podendo ser observado no histórico de suas políticas públicas, também não pode ser trabalhado enquanto prática de um determinado grupo político ou exclusividade de uma figura de representação, pois o retorno dessa pauta no ano de 2004 durante uma gestão trabalhista, onde foi aprovada a Lei 11.079/2004 que institui as Parcerias PúblicoPrivadas (PPP's) (BRASIL, 2004), outorgou aos municípios o poder concedente de serviços, definindo regras gerais para licitações e contratações de PPP's, permitindo que após décadas de embates entre movimentos sociais e o Estado houvesse a legitimação para a realização de concessões.

A plena concretização do projeto se deu quando foi sancionado a Lei 11.445/2007 que estabelece a Lei Nacional do Saneamento Básico (LNSB) (BRASIL, 2007), apresentada enquanto um grande avanço para a universalização dos serviços de saneamento, e que planificou a Lei 11.079/2004. A PNSB ainda determinou que os municípios fizessem a elaboração de seus planos locais de saneamento, e definissem os horizontes para a prestação dos serviços.

Tal reflexão, das primeiras iniciativas para a organização do EBESB, visitando o desenvolvimento das políticas de saneamento básico até a metade da primeira década do 
século XXI, possibilita vislumbrar a utilização histórica das políticas sociais como instrumento de legitimação de modelos de Estado, governo e ordem política. E deste modo, é possível considerar que no Brasil o modelo de Estado de Bem-Estar Social não seja protetor, mesmo diante das realizações que se deram entre os anos de 1930 e 1964 e na CF de 1988, diferentemente do que ocorreu nos Estados de Bem-Estar Protetores, onde o mesmo cumpriu um papel importante para a proteção social, através do financiamento de políticas protetoras "desde la cuna a la tumba" (GIMENO, 2017, p. 39).

Segundo Santos (2009; 2001), o modelo brasileiro enraíza-se na planificação de um modelo político corporativista, empreendido abaixo dos interesses do capital, constituído enquanto receptáculo das consequências da expansão capitalista, que devora os recursos públicos ao orientá-los para investimentos econômicos em detrimento da garantia de direitos sociais.

Permanece, portanto, o questionamento sobre as alterações possibilitadas pelas mudanças na Legislação Federal após 2007, que se fará através da reflexão sobre sua influência no plano local de saneamento básico do município de Pelotas, buscando compreender se neste processo ocorreu uma mudança de paradigma? Se existe uma reorientação nas políticas sociais em curso no Brasil que possa ser observada nesta relação? Ainda, se esta mudança representa algo novo, em termos de transformação? E, como a legislação em vigor pode interferir em uma mudança cognitiva no que tange a orientação da política? Estas são algumas das questões que se procurará compreender na reflexão no próximo subitem sobre a PNSB e na sua planificação, através do PMSB desenvolvido no município de Pelotas-RS.

\section{Breve reflexão sobre a política de habitação ontem e hoje: é possível que esteja em curso uma reestruturação discursiva?}

A criação do Programa habitacional Minha Casa Minha Vida (PMCMV) por parte do Governo Federal, possibilitou na última década o desenvolvimento de um número significativo de habitações no país, sobre os quais pesa um estigma - desenvolvimento de bairros e condomínios distante dos centros das cidades. Um modelo de desenvolvimento excludente, que potencializa processos de estratificação social. Sobre este modelo de desenvolvimento urbano se abre a possibilidade de uma série de análises, que são entendidas enquanto necessárias para que se possa lançar as bases da discussão que se pretende fazer. 
Este processo, como a literatura especializada tem demonstrado (BOULOS, 2015; MARICATO, 2015; ROLNIK, 2015), possibilita a aquisição de terras a baixo custo e vendas com suntuosas taxas de lucro, colaborando para a segregação sócio-espacial não somente de camadas da população encontradas em situação de vulnerabilidade (MARICATO, 2015). Desencadeando assim, o processo de fortalecimento de alienação urbanística (ROLNIK, 2015), especulação imobiliária e obtenção da mais valia relativa (BOULOS, 2015). Os grupos lançados neste processo, acabam por necessitar a curto prazo, de uma série de equipamentos e serviços que tais localidades não possuem, e que necessitam ser desenvolvidos, desta forma potencializando as questões anteriores.

Assim, se pode vislumbrar que, por este processo ser instituído através de recursos e programas estatais, acaba por estruturar uma sólida base para novas retóricas. Pois através da transferência de recursos, ou financiamento do Estado à iniciativa privada - como é o caso do PMCMV, se desenvolve o discurso de garantia do direito à moradia, que em última instância serve para mistificação e manutenção deste processo de exclusão. E ainda oculta a questão fundiária urbana, de supervalorização das regiões centrais, instituindo processos de autosegregação e reprodução do discurso estatal por parte daqueles que estão sendo vítimas de segregação.

Ademais, este processo cria ainda a oportunidade de seleção e movimentação de grupos específicos para territórios escolhidos, próximos ou distantes dos centros, estratificação das relações sociais e focalização de bolsões de pobreza. Desenvolvem-se processos de exclusão, que empurraram trabalhadores para áreas periféricas, para potencialização dos lucros por parte da iniciativa privada e aprofundamento da lógica produtivista neoliberal - novas retóricas que camuflam velhas políticas neoliberais (GIMENO, 2017).

Sposito (1988, p. 75), destaca que "as contradições sociais impostas pelo desenvolvimento capitalista estão impressas na estrutura e na paisagem urbana. A opção do Estado parece clara [...]". Complementarmente, Silva (1989), ao discorrer sobre a política habitacional brasileira após 1964, apresenta a intrínseca relação desta com a busca de legitimidade do governo que acabara de se instaurar no país através do golpe civil militar. No referido texto a autora trabalha a relação da política com a intenção do Estado em justificar suas "boas intenções" para com a sociedade maquiando seu real objetivo:

Além da busca de legitimação do novo regime, a política habitacional em formulação se propunha, também, a criar um clima de "estabilidade social" e de "ordem" necessário ao avanço do capitalismo internacional no país. Essa função é ilustrada pelas seguintes palavras de 
Roberto Campos, um dos idealizadores da política habitacional: "A solução do problema para a casa própria tem esta particular atração de criar o estímulo de poupança que, de outra forma, não existiria e contribui muito mais para a estabilidade social do que o imóvel de aluguel. O proprietário da casa própria pensa duas vezes antes de se meter em arruaças ou depredar propriedades alheias e torna-se um aliado da ordem" (SILVA, 1989, p. 49).

A ideologia de comprometimento da classe trabalhadora com a ideologia burguesa de manutenção da propriedade privada neste processo, demonstra o comprometimento do Estado com a manutenção política, econômica e simbólica do sistema. Vale destacar ainda, que o sistema de operacionalização da política habitacional dava-se através do financiamento público, e que para tanto, o Estado passou a recolher:

$8 \%$ sobre as folhas de pagamento dos empregados por parte dos empregadores, liberando estes da indenização obrigatória [...] representou a extinção da estabilidade no trabalho, ocasionando sérios prejuízos para o trabalhador em termos de permanência nos empregos e no valor dos salários recebidos (SILVA, 1989, p. 53).

A política de habitação que era de administração das caixas de pecúlio e órgãos previdenciários até 1964 , passou a ser administrada pelo BNH, juntamente com os recursos para obras de saneamento - como anteriormente exposto. Recursos estes, utilizados para o financiamento do setor privado, que era responsável pelas obras: "uma política de centralização normativa e descentralização executiva" (SILVA, 1989, p 53), que se comprometia com a ideologia econômica e política vigente, para manutenção dos setores privados da economia.

Quando as políticas habitacionais desenvolvidas no país após 1964, são relacionadas com as políticas habitacionais desenvolvidas após o ano de 2007 - quando fora criado o Programa de Aceleração do Crescimento (PAC) - Lei 11.578 (BRASIL, 2007) - é possível de ser observado que, da mesma forma como apresenta Silva (1989) as políticas adotadas durante o regime militar, o PMCMV, estruturado a partir do PAC, enuncia-se enquanto programas para o crescimento do país através do desenvolvimento econômico, gerando soluções para problemas estruturais históricos, mas, não indo além da retórica, da propaganda para a manutenção do poder e potencialização dos financiamentos públicos ao setor privado (RODRIGUES; SALVADOR, 2011).

Em nenhum dos casos a estrutura do Estado para o desenvolvimento de políticas urbanas se alterou, substituíram-se os órgãos financiadores - o BNH pela Caixa Econômica Federal - como também os projetos de habitação - COHAB por Minha Casa minha Vida. Ainda assim, não foi desenvolvida uma política urbana, e sim, reestruturou-se o modelo de 
transferência de recursos públicos para o financiamento de construção de moradias, de obras de saneamento e transporte (MARICATO, 2015; ROLNIK, 2015).

A pauta da política urbana e da participação popular desenvolvida nos processos pré CF de 1988, que fortaleceram o tencionamento pelo estabelecimento do espaço para emendas de iniciativa popular no âmbito do projeto, conferiram "uma oportunidade massivamente aproveitada de participação popular, quando foram encaminhadas mais de doze milhões de assinaturas para as emendas que foram propostas ao projeto em discussão na Constituinte" (MATOS, 2010, p. 24). Contudo, acabou sendo esvaziado enquanto processo real de incidência na política, mantendo-se enquanto uma espécie de performance simbólica, ligada a arqueologia do processo democrático anterior.

Desta forma, o discurso enunciado pelo Estado na última década, que fora aguardado pelos movimentos sociais organizados, mostrou-se infrutífero, pois as disposições previstas no PAC foram "uma série de medidas de caráter econômico visando a manutenção da estabilidade econômica e o cumprimento de acordos internacionais" (RODRIGUES E SALVADOR, 2011, p.131). Compreende-se, portanto, que um Estado subjugado por uma classe dominante, planeja seus investimentos para que esta aumente seu poder e acumulação, e encrava na exclusão uma de suas principais estratégias de manutenção, somado ao controle político do poder e burocratização estatal, objetivando o domínio sobre a economia.

Desta forma, se aprofundam os processos de segregação e exclusão, pela reprodução de práticas coloniais que intentam a garantia dos interesses das elites dominantes (VAINER, 2013), um modelo enraizado na estrutura política nacional que se impõem aos territórios através da perpetuação da negação ao acesso democrático a serviços e equipamentos coletivos, resultante e resultando da negação à participação nos processos políticos.

Assim, o trato de questões sociais quando abordadas na configuração que se tem observado, possibilita o desenvolvimento cognitivo da responsabilização individual sobre os processos de fragilização social e vulnerabilidade, traduzida na apreensão meritocrática da realidade, reforçada pelo discurso da educação para o trabalho, ocultando a usurpação de direitos, e impossibilitam o reconhecimento dos macro processos políticos e econômicos, que mesmo diante da não garantia de direitos consegue criar a sensação de que a ação do Estado desenvolve-se neste sentido.

Tal reflexão, aponta para um modelo de gestão específico, que perpassa o desenvolvimento sócio-histórico e político do Estado brasileiro. Este que condiciona o desenvolvimento de suas políticas sociais, alinhando a perspectiva das políticas à garantia de 
continuidade e manutenção do modelo de EBESB. Um modelo conciliador, que se sustenta pela mediação das relações de classe e ocultação dos conflitos sociais. Modelo gestado através da elaboração e execução das políticas públicas de cunho populista verticalizada. Não configurando um processo democrático real, que perpetua uma pré-determinada ordem societária, fundamentada na exclusão e acumulação. Mas há uma mudança de paradigma?

\section{Política Nacional e Plano Municipal de Saneamento Básico: instrumentos, métodos, valores e discursos em disputa}

Fazendo uma breve revisão dos processos desenvolvidos e até aqui relatados, pode-se apontar para dois movimentos no desenvolvimento das políticas sociais brasileiras: um primeiro de caráter populista, voltado para o desenvolvimentismo, onde se inaugura o modelo de EBESB, que é diferente do modelo Europeu, não sendo considerado nesta escrita enquanto protetor, mas através do qual desenvolveram-se instrumentos de proteção. Este movimento, não anula o segundo, mas busca trabalhar em conformidade com o mesmo, aqui abordado enquanto um movimento "quase" que sequencial das reformas e reestruturação das políticas sociais brasileiras, onde buscou-se continuamente $\mathrm{o}$ alinhamento às políticas e imposições internacionais, pautando-se nos macroprocessos do capitalismo global.

Tal afirmativa, esbarra em um "quase" pela compreensão de que as crises cíclicas do modo de produção capitalista, que se intensificaram nas últimas décadas: 1920 até 1930, somente tendo sido resolvida pela Segunda Guerra Mundial (DANTAS, 2009); fim da década de 1960 até 1980, momento de reestruturação produtiva do capital; crise 2007/2008, que tem sido apontada enquanto a maior crise do capitalismo pós Guerra (DANTAS, 2009), bem como as transformações geopolíticas que se deram no período de 1950 e o meio da década de 1980, acabaram por se traduzirem em um imperativo para a interferência internacional no Brasil.

Deste modo, ao observar as reflexões sobre as mudanças estruturais que conduziram a uma transformação do paradigma da proteção social na Europa, e sobre as bases até aqui desenvolvidas, analisa-se o PMSB na intenção de compreender como a PNSB materializa-se neste, e de que forma PMSB normatiza a execução da política nacional. Compreendendo que a diretriz Federal relaciona uma série de agentes de diferentes áreas de atuação profissional, 
propondo a estes ação conjunta no desenvolvimento de instrumentos democráticos para a construção dos planos e execução das obras, o rigor teórico-metodológico de sua planificação é fundamental para que os agentes possam reconhecer-se mutuamente no processo para sua execução, e alcançar tais objetivos (GIMENO, 2017; DANTAS, 2009).

Destaca-se ainda que, segundo a PNSB o desenvolvimento dos PMSB é imperativo para que os municípios acessem recursos para a execução de obras de saneamento contratadas com recursos federais. Neste contexto, foi a partir do ano de 2009 que o município de Pelotas passou a desenvolver projetos e enviar para o Ministério das Cidades através do PAC para o acesso a recursos financeiros para a execução de obras.

Importante evidenciar, que diante de todas as formas de acesso a recursos disponíveis aos municípios, encontra-se nas exigências da PNSB que se tenham projetos de trabalho social que possibilitem a participação popular a ser desenvolvidos paralelamente a execução das obras - proposta esta, que aponta para uma reconfiguração das políticas através da participação popular, alinhando-as ao que fora estabelecida na CF de 1988, mas que até então carecia de regulamentação. Desta forma, todos os projetos que buscam o acesso à recursos para planificação da PNSB, tem de lidar ainda com a obrigatoriedade instituída pela Portaria 21 de apresentarem juntamente aos projetos de obras, projetos de trabalho de mobilização social entre outros (BRASIL, 2014).

Deste modo, pode-se iniciar a discussão sobre o PMSB entendendo-o não enquanto uma demanda local, dada a compreensão da necessidade de uma discussão ampliada com a sociedade, ou da importância da participação social na execução das políticas, em que o saneamento, bem como o acesso a água são direitos humanos fundamentais, sendo urgente a discussão quanto a seu acesso e universalização. Mas sim, porque se não houvesse um PMSB os recursos não seriam disponibilizados ao município.

Desse modo, após um longo processo de busca pelo documento do PMSB para análise devendo este ser de acesso público - o mesmo fora acessado somente em formato de Power Point (PELOTAS, 2010), sob a alegação de indisponibilidade devido ao mesmo não ter sido aprovado pela câmara de vereadores de Pelotas, não existindo ainda um documento oficial (informação verbal) ${ }^{4}$. O que leva ao questionamento sobre como se deu a liberação de recursos públicos federais para a execução das obras sem a aprovação de PMSB ou ainda sem um documento oficial?

\footnotetext{
${ }^{4}$ Informação fornecida por Aline Cunha da Fonseca; Assistente Social do Trabalho Sócio Ambiental da autarquia responsável pelo serviço em entrevista realizada em abril de 2016.
} 
A busca pelo documento levou os pesquisadores a fazer contato com o executivo e o legislativo municipal a fim de se obter esclarecimentos, mas os mesmos não retornaram os contatos. Desta forma, buscou-se a direção da autarquia responsável pelos serviços de saneamento no município - SANEP - onde não se tinha conhecimento sobre tal documento, sendo o mesmo encontrado em poder de um dos engenheiros da instituição, apontado como responsável por sua elaboração (informação verbal) ${ }^{5}$.

Desta forma, com o acesso ao documento pode ser realizada a análise. Este estruturase em duas vertentes, sendo uma denominada "Embasamento Legal" e a outra "Marco Regulador", estas organizam de forma sintética o marco regulatório para o setor de saneamento do município - Lei 11.445. O documento traz também, os Planos Diretores de Água, Esgotamento Sanitário, e as Ações para Emergências e Contingências; sendo finalizado com as Considerações Finais.

Tal documento não ultrapassa os limites de um relatório sobre os atuais sistemas de captação e tratamento de água e esgoto existentes no município, encerrando com o apontamento de um conjunto de obras que necessitam ser desenvolvidas de forma emergencial para solucionar os problemas de abastecimento de água e tratamento de esgoto, com seus respectivos orçamentos - um pré-projeto para captação de recursos.

O PMSB não desenvolve estratégias para a planificação da PNSB sobre nenhum dos itens de participação social, traduzindo a questão referente ao saneamento básico enquanto um conjunto de obras, canos, buracos e cifras. Descaracterizando assim, a abrangência das Políticas Públicas e Sociais, fragmentando e fragilizando sua compreensão. Situação esta, que pode ainda vir a causar os mais variados tipos de ruídos entre seus agentes planificadores.

A abordagem do PMSB ao tratar a política pública enquanto um conjunto de obras oculta o fato de que a distribuição dos impactos pela falta de acesso a estes serviços é desigual e estratificada. E mesmo diante da execução das obras previstas, parte significativa da população continuará sem os serviços, devido ao direcionamento que tem sido dado a estes que objetivam a resolução de problemas causados pelo desenvolvimento do setor imobiliário local, não respondendo às demandas daqueles que tem sofrido diante dos processos de exclusão, desenvolvidos em grande parte pelo elevado aumento que ocorreu nos valores dos imóveis e alugueis nos últimos anos, através do chamado boom imobiliário pós 2008, que acabou por aumentar o número daqueles que se deslocam para cada vez mais distante dos

\footnotetext{
${ }^{5}$ Informação fornecida por Aline Cunha da Fonseca; Assistente Social do Trabalho Sócio Ambiental da autarquia responsável pelo serviço em entrevista realizada em abril de 2016.
} 
centros urbanos, e acabam alocando-se em áreas de risco: ocupações à beira de córregos, canais, sangas, etc. (BOULOS, 2015) - áreas ocupadas de forma irregular, que por este motivo acabam não sendo documentadas.

Por conta do PMSB não contemplar as ações de controle e participação social, os grupos assolados pelos mais graves problemas acabam não sendo ouvidos, e os problemas que os assolam cotidianamente mantém-se na clandestinidade. Neste ínterim, ao afirmar a necessidade da participação social nos momentos de tomadas de decisão, a PNSB busca aproximar a sociedade à temas de grande relevância social, fazendo com que sejam criados espaços de envolvimento e participação popular, pela construção de ferramentas democráticas de controle social. Carola Castellà e Marc Parés (2012) afirmam a necessidade da participação popular na tomada de decisões quanto à utilização de recursos públicos, reforçando a ideia de que a participação cidadã tem influência na qualidade da elaboração de políticas públicas.

Partimos da convicção de que é preciso contar com os cidadãos na hora da tomada de decisões coletivas e, por isso, é necessário habilitar espaços de participação cidadã para tomada de decisões públicas. Entendemos participação cidadã como "qualquer atividade dirigida a influir direta ou indiretamente nas políticas públicas" [...] A participação cidadã transcende de fato os limites do estritamente político e coloca os cidadãos nas esferas de decisão e execução do público a partir do cotidiano, ou seja, desde sua experiência diária e da proximidade com o processo de tomada de decisões nos bairros (CASTELLÀ; PARÉS; in TENÓRIO, 2012, p. 210).

Os autores destacam que os déficits de eficácia dos mecanismos decisórios têm se dado principalmente pela falta de legitimidade e funcionalidade dos processos, o que gera críticas quanto a estes no que diz respeito à falta de representação e rigidez dos espaços de representatividade, que acabam por dificultar a participação popular.

O aumento desta participação por meio de instrumentos deliberativos ou de representação direta seriam os objetivos a serem alcançados, o que vem a corroborar com a perspectiva trabalhada pela PNSB, ao buscar a desconstrução da contradição criada entre os conceitos de participação popular e eficiência, pois estes devem ser trabalhados cada vez mais de forma complementar. A aproximação da sociedade junto a elaboração, execução e fiscalização das políticas públicas - sendo este processo compreendido enquanto participação democrática - tende a qualificar as mesmas, na medida em que o cidadão é o afetado em seu cotidiano pela falta destas políticas (CASTELLÀ; PARÉS, 2012), para além, é o sentido retórico do desenvolvimento da política. 
Retórico, porque a análise histórica do desenvolvimento das políticas públicas somado a não fiscalização dos processos - verificada no acesso à recursos com um plano sem as devidas aprovações locais - reforçam os apontamentos anteriores quanto à aparência e essência do desenvolvimento das políticas públicas nacionais.

Mesmo a PNSB apontando para a garantia da prestação dos serviços de saneamento em sua universalidade e integralidade (Art. $2^{\circ}$, incisos I, II, respectivamente), considerando que a participação traz a experiência que parte de práticas e vivências cotidianas (CASTELLÀ; PARÉS; in TENÓRIO, 2012), o que propicia a construção de instrumentos para o acesso em conformidade com as necessidades locais, maximizando a eficácia das ações e seus resultados (BRASIL, 2007).

Buscando a integração do PNBS a outras políticas consideradas de relevante interesse social considerando as demandas emergentes em uma realidade multifacetada e não linear (GAMA, 2010), tais efeitos não foram reproduzidos no PMSB, e a análise deste documento ainda reflete formalmente que não há diálogo entre os documentos, e tão pouco respeito às garantias da CF de 1988, planificadas quanto a participação social.

Ao passo que a PNSB destina um capítulo inteiro para trabalhar à participação de órgãos colegiados de caráter consultivo no controle social da política de saneamento, através dos quais assegura a participação social dos usuários do serviço de saneamento e da sociedade civil organizada (capítulo VIII), este viés não fora admitido na legislação anterior (Lei 5.318/67), por razões que parecem inerentes ao regime ditatorial militar, também não o é no PMSB, podendose verificar a aproximação das discussões que sustentam a exclusão da participação social, imbricada com um conceito de organização política e gestão pública que rejeita a participação social, trabalhando as políticas públicas de forma verticalizada com tendência ao beneficiamento de grupos seletos. Ao voltar-se ás populações em situação de vulnerabilidade a ação estatal assume caráter assistencialista, mistificando as relações, negando os direitos e gerando o sentimento de favorecimento.

\section{CONCLUSÃO}

Compreende-se que a breve análise sobre o desenvolvimento do EBESB levou a reflexão de que este se diferencia dos Estados de Bem-Estar Protetor Europeu. Contudo, ainda assim o EBESB até o ano de 1964 desenvolveu importantes estratégias e instrumentos de proteção social, sobretudo para os trabalhadores. Sendo que, após a CF de 1988 tantos outros avanços 
foram alcançados, aqui recebendo destaque a participação social em tais processos, porém, ainda necessitando ser ampliados, à exemplo: através da universalização do acesso a saúde e a criação de um Sistema Único de Assistência Social, entre outros.

No tocante ao desenvolvimento histórico da intervenção estatal sobre as políticas voltadas para a questão da habitação - BNH e PMCMV, é evidente o desenvolvimento de estratégias para a transferência de recursos públicos para a iniciativa privada nos dois momentos em que tal questão fora trabalhada enquanto política federal, da mesma forma como também se evidenciam os discursos de garantia de direitos que ocultam o comprometimento ideológico dos trabalhadores não somente com a manutenção da propriedade - uma cristalização da racionalidade burguesa, mas com uma transformação estrutural pautada em um comprometimento cognitivo.

Finalmente, a reflexão sobre a PNSB e sua planificação através do PMSB do município de Pelotas, vem a representar a continuidade de estruturas que apontam para o distanciamento da sociedade dos processos de participação social, como na criação do CONSANE, onde não houve o desenvolvimento de instrumentos de aproximação ou democratização de gestão da política, que continuou a ser abordada de forma tecnicista, autoritária e verticalizada, ou como na operacionalização do primeiro plano nacional de saneamento, o PLANASA, extinto sem sua concreta execução. Mais uma vez negando a essência e eficácia da democracia e favorecendo a manutenção do paternalismo, populismo e caridade estatal.

A análise do desenvolvimento das políticas públicas nacionais historicamente aponta para o contínuo da transferência de recursos públicos para os setores privados da economia, mistificado em uma pretensa garantia de direitos sociais, onde se desenvolvem instrumentos de participação que não são efetivados em sua plenitude, ou são cooptados pelo Estado para a continuidade das estratégias de manutenção deste modelo de desenvolvimento que impõem a máxima exploração aos países subdesenvolvidos.

A complexidade dos eventos narrados ao ser analisada de forma crítica e dialética, possibilita o enfatizar das interconexões e interdependências sistêmicas observadas na historicidade dos acontecimentos, explicita os conflitos e contradições inerentes ao sistema capitalista e a condição das classes (LOUREIRO; LAYRARGUES; CASTRO, 2002). Desta forma desvelando os mecanismos que escamoteiam a produção e reprodução da desigualdade na desresponsabilização do Estado por esta. Produzindo-se a exclusão e cristalizando-se a divisão social, através da criação dos guetos territoriais e cógnitos que negam a garantia da existência 
coletiva e de seus direitos, buscando o silenciar ideológico dos grupos que se encontram em desvantagem nesta disputa.

A narrativa construída ao justificar a opção de análise na planificação da PNSB, buscou a identificação dos processos participativos instituídos por esta compreendendo que os mesmos historicamente foram negados, ocultados ou inviabilizados, e que a falta desta aproximação tende a desqualificar os processos abrindo zonas cinzentas, duvidosas, que geram 0 afastamento por parte das populações usuárias das políticas quanto a sua elaboração, execução e fiscalização. Processo este que fragiliza na essência a democracia, mas encontra-se enraizado na essência do desenvolvimento e execução das políticas públicas brasileiras, o que é reforçado na observação do PMSB, ao não reconhecer o direito a participação social, e não ser alvo de fiscalização e tão pouco sanção, o que corrobora com uma apreciação que aponta para o uso da PNSB com caráter assistencialista.

Uma vez que uma mudança de paradigma na política implica na transformação de sua estrutura, instrumentos, métodos e técnicas que levaram a uma nova interpretação da natureza dos problemas sociais e consequentemente na forma de racionalizá-los, que vem a alterar a apreensão das raízes dos problemas e assim a forma de se operacionalizar a intervenção sobre os mesmos. Tal reflexão sobre os processos brasileiros não pode desenvolver-se de forma simplista, pois as aproximações e distanciamentos discursivos históricos, bem como as orientações das práticas políticas tornam tal análise sobremodo complexa.

As transformações na legislação em âmbito nacional da última década carregam contradições que afastam sua lógica discursiva da concretização das ações, enfraquecendo direitos sociais, e como no caso do PAC, retirou recursos da Política de Educação e Seguridade Social, transferindo a iniciativa privada (RODRIGUES; SALVADOR, 2011), fundamentando as atuais reformas políticas e sociais na continuidade dos processos anteriores, fragilizando os trabalhadores e tendendo a potencializar processos de empobrecimento em massa, ao passo que multiplica a acumulação de capital para poucos. No Brasil, as novas e velhas retóricas complementam-se, e a mudança de paradigma não se encrava nelas, mas sim na reorientação estrutural e prática das políticas que torna a austeridade uma constante na política nacional.

Há uma mudança de paradigma político? Sim. Ocorre o retorno a velhas políticas neoliberais, sob novas retóricas? Não, pois o modelo de implementação de políticas sociais calcadas na perspectiva neoliberal foi constante nas últimas décadas, e as variações retóricas se deram mais por conta de orientações partidárias do que por questões estruturais. A exemplo disso, o discurso desenvolvimentista do governo trabalhista não rompeu com os ideais de 
governos anteriores, e consolidou-se na retirada de recursos orçamentários que eram destinados às políticas sociais, sendo os principais: o Programa de Integração Social (PIS), Contribuição para o Financiamento da Seguridade Social (CONFINS) e a Contribuição Social Sobre o Lucro Líquido (CSLL) - contribuições sociais destinadas à manutenção da política de Seguridade - saúde, assistência e previdência social.

Portanto, gerou-se recursos para transferência à iniciativa privada, mantendo-se a orientação dos gastos públicos de forma comprometida com a manutenção da desigualdade, reduzindo em termos reais os investimentos para com a proteção social. Em concordância com Gimeno (2017), tais práticas políticas têm sido observadas independentemente da orientação ideológica do governo, seja ele de centro-direita ou centro-esquerda - transforma-se o discurso, se mantém a estrutura, e não se rompe com a lógica de desenvolvimento.

Sem cair em reducionismos mecanicistas, mas buscando considerar suas múltiplas determinantes e construir sínteses por meio destas, compreende-se que o problema para a análise da situação do modelo de EBESB, é que o mesmo nunca fora protetor, e sim desenvolveu ações de proteção, restando a questão de que, se desta forma poder-se-á apontar para uma mudança de paradigma? Acredita-se que sim, pode-se vislumbrar a redução nos investimentos do Estado para proteção social, retirada de direitos e retorno ao assistencialismo, na revisitação a políticas privatistas bem como a adoção da austeridade como prática política. Mas mesmo diante deste quadro não é possível afirmar que esta seja uma transformação no sentido apontado por Gimeno, (2017) - de estado Protetor para Inversor.

\section{REFERÊNCIAS}

BARCELLOS, T. A Política Social Brasileira 1930-64: evolução institucional no Brasil e no Rio Grande do Sul. Porto Alegre: Fundação de Economia e Estatísticas, 1983.

BOULOS, G. Por que ocupamos? Uma introdução a luta dos sem teto. São Paulo: Autonomia Literária. 2015.

BRASIL. Constituição da República Federativa do Brasil de 05 de outubro de 1988. Brasília, DF, 1988.

Decreto № 19.402, de 14 de novembro de 1930. Cria uma Secretária de Estado com a denonimação de Ministério dos Negócios da Educação e Saude Publica. Disponível em: 
<http://www2.camara.leg.br/legin/fed/decret/1930-1939/decreto-19402-14-novembro-1930515729-publicacaooriginal-1-pe.html>. Acessado em: 24 jul. 2017.

Lei № 200 de 25 de fevereiro de 1967. Dispõe sobre a organização da Administração Federal, estabelece diretrizes para a Reforma Administrativa e dá outras providências. Brasília, DF, 1967.

Lei no 4.380 de 21 de agosto de 1964. Institui a correção monetária nos contratos imobiliários de interesse social, o Sistema Financeiro para a Aquisição da Casa Própria, cria o Banco Nacional de Habitação (BNH), e Sociedades de Crédito Imobiliário, as Letras Imobiliárias, o Serviço Federal de Habitação e Urbanismo e dá outras providências. Brasília, DF, 1964.

Lei no 5.318 de 26 de setembro de 1967. Institui a Política Nacional de Saneamento e cria o Conselho Nacional de Saneamento. Brasília, DF, 1967. Disponível em: < Disponível em: < http://www2.camara.leg.br/legin/fed/lei/2007/lei-11578-26-novembro-2007-564416normaatualizada-pl.pdf>. Acessado em: 24 jul. 2017.> Acesso em: 24 jul. 2017.

Lei no 5.762 de 14 de dezembro de 1971. Transforma o Banco Nacional da Habitação (BNH) em empresa pública, e dá outras providências.. Brasília, DF, 1971.

Lei no 11.578, de 26 de novembro de 2007. Dispõe sobre a transferência obrigatória de recursos financeiros para a execução pelos Estados, Distrito Federal e Municípios de ações do Programa de Aceleração do Crescimento - PAC, e sobre a forma de operacionalização do Programa de Subsídio à Habitação de Interesse Social - PSH nos exercícios de 2007 e 2008. Disponível em: < http://www2.camara.leg.br/legin/fed/lei/2007/lei-11578-26-novembro-2007564416-normaatualizada-pl.pdf>. Acessado em: 24 jul. 2017.

Lei no 11.445, de 5 de janeiro de 2007. Estabelece diretrizes nacionais para o saneamento básico; altera as Leis nos 6.766, de 19 de dezembro de 1979, 8.036, de 11 de maio de 1990, 8.666, de 21 de junho de 1993, 8.987, de 13 de fevereiro de 1995; revoga a Lei no 6.528, de 11 de maio de 1978; e dá outras providências. Disponível em: < http://www.planalto.gov.br/ccivil_03/_ato2007-2010/2007/lei/l11445.htm>. Acessado em: 24 jul. 2017.

Ministério do Desenvolvimento Social e Combate à Fome. Orientações Técnicas: Centro de Referência de Assistência Social - CRAS. - CRAS. - Brasília, DF: Secretaria Nacional de Assistência Social, 2011.

Ministério do Planejamento, Orçamento e Gestão. Programa de Aceleração do Crescimento: 2007-2010. Brasília. 22 de janeiro de 2007. 82 slides. 
Portaria 21 de 22 de janeiro de 2014. Aprova o Manual de Instruções do Trabalho Social nos Programas e Ações do Ministério das Cidades. Disponível em: <http://www.habitacao.sp.gov.br/casapaulista/downloads/portarias/portaria_21_01jan_22_20 14_manual_inst_trabalho_social.pdf> Acesso em: 24 jul. 2017.

BORJA, P. Política pública de saneamento básico: uma análise da recente experiência brasileira. São Paulo: Saúde Soc , 2014.

CASTELLÀ, C; PARÉS, M. Participação e qualidade democrática: uma proposta de critérios de qualidade. in TENÓRIO, F. G. Cidadania e desenvolvimento local: critérios e analises, Rio de Janeiro: FGV, 2012.

CAUBET, C. G. A água, a lei, a política... E o meio ambiente? Curitiba: Juruá, 2004.

CYNAMON, Szachna Eliasz. Política de Saneamento: proposta de mudança. Cad. Saúde Pública [online]. 1986, vol.2, n.2, pp. 141-149. ISSN 1678-4464

DANTAS, R. A grande crise do capital. Cadernos de Ética e Filosofia Política. P 47 - 72, no 14. jan. 2009. São Paulo: Editora da USP. Disponível em: < http://www.revistas.usp.br/cefp/article/viewFile/82984/86032> Acesso em: 24 jul. 2017.

DRAIBE, S; HENRIQUE, W. Welfare State, Crise e Gestão da Crise: Um Balanço da Literatura Internacional. in Revista Brasileira de Ciências Sociais (ANPOCS), n.o 06, vol. 03; 1988.

As Políticas Sociais Brasileiras: diagnósticos e perspectivas. In: Para a Década de 90: prioridades e perspectivas de políticas públicas - Políticas Sociais e Organização do Trabalho. Brasília: IPEA, 1989.

FALEIROS, V. de P. A política social do Estado Capitalista. São Paulo. Cortez, 2000.

GAMA, R. S. Aspectos da Política Nacional de Saneamento diante da transição democrática da sociedade e do Estado brasileiro. Revista Desenvolvimento e Meio Ambiente, n. 22, p. 141-152, jul./dez. Editora UFPR, 2010. 
GIMENO, J. A. Reestructuración de los Estados del Bienestar ¿Hacia un cambio de paradigma? Argumentum, Vitória, v. 9, n. 2, p. 38-52, maio/ago. 2017.

LOUREIRO, C. F. B; LAYRARgueS, P. P; CASTRO, R. S. (orgs.). Sociedade e Meio Ambiente: a educação ambiental em debate. 3ạ edição. São Paulo: Cortez, 2002.

MATOS, A. B. Direito à cidade, plano diretor e gestão participativa: O caso-referência de Paraty. Dissertação apresentada ao Programa de Pós-Graduação em Direito da PUC-Rio como requisito parcial para obtenção do título de Mestre em Direito. 2010.

MARICATO, E. Para entender a crise urbana. São Paulo: Expressão Popular. 2015.

MEDEIROS, Marcelo. Trajetória do Welfare State no Brasil: papel redistributivo das políticas sociais dos 1930 aos anos 1990. Texto para discussão no 852 Brasília: IPEA. 2001.

PELOTAS. Plano Municipal de Saneamento Básico. Serviço Autônomo de Abastecimento de Água e Esgoto (SANEP). Pelotas 14 de abril de 2016. 127 slides. Apresentação em Power Point.

RODRIGUES, T. A; SALVADOR, E. As implicações do Programa de Aceleração do Crescimento (PAC) nas Políticas Sociais. Brasília: SER Social, v. 13, n. 28, p. 129-156, jan/jun. 2011.

ROLNIK, R. Guerra dos Lugares: a colonização da terra e da moradia na era das finanças. São Paulo: Boitempo. 2015.

SANTOS, M. A urbanização Brasileira. 5 ed. São Paulo: Editora Universidade de São Paulo, 2009 A Urbanização desigual: a especificidade do fenômeno urbano em países subdesenvolvidos. Petrópolis: Vozes, 2001.

SILVA, M. O. S. Política Habitacional Brasileira: verso e reverso. São Paulo: Cortez, 1989.

SPOSITO, M. E. B. Capitalismo e Urbanização. São Paulo: Contexto, 1988. 
TENÓRIO, F. G. Cidadania e desenvolvimento local: critérios e analises, Rio de Janeiro: FGV, 2012.

VAINER, C. A Cidade do Pensamento Único: desmanchando consensos. Petrópolis, RJ: Vozes, 2013.

Trabalho enviado em 22 de março de 2018

Aceito em 02 de junho de 2018 